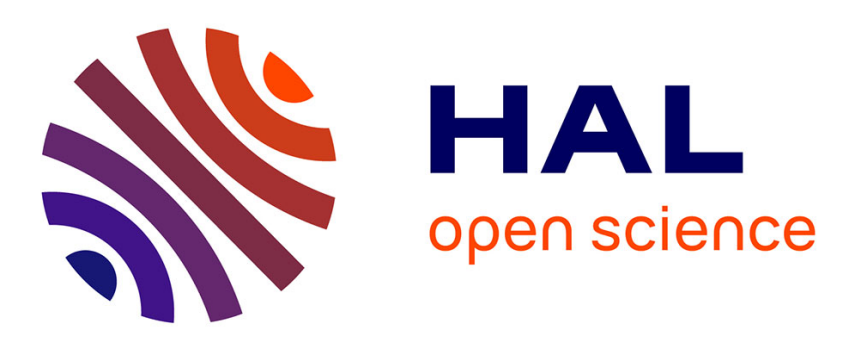

\title{
Kinetics of Water Adsorption in Microporous Aluminophosphate Layers for Regenerative Heat Exchangers
}

Hendrik van Heyden, Gunther Munz, Lena Schnabel, Ferdinand Schmidt, Svetlana Mintova, Thomas Bein

\section{To cite this version:}

Hendrik van Heyden, Gunther Munz, Lena Schnabel, Ferdinand Schmidt, Svetlana Mintova, et al.. Kinetics of Water Adsorption in Microporous Aluminophosphate Layers for Regenerative Heat Exchangers. Applied Thermal Engineering, 2009, 29 (8-9), pp.1514. 10.1016/j.applthermaleng.2008.07.001 . hal-00540586

\section{HAL Id: hal-00540586 \\ https://hal.science/hal-00540586}

Submitted on 28 Nov 2010

HAL is a multi-disciplinary open access archive for the deposit and dissemination of scientific research documents, whether they are published or not. The documents may come from teaching and research institutions in France or abroad, or from public or private research centers.
L'archive ouverte pluridisciplinaire $\mathbf{H A L}$, est destinée au dépôt et à la diffusion de documents scientifiques de niveau recherche, publiés ou non, émanant des établissements d'enseignement et de recherche français ou étrangers, des laboratoires publics ou privés. 


\section{Accepted Manuscript}

Kinetics of Water Adsorption in Microporous Aluminophosphate Layers for Regenerative Heat Exchangers

Hendrik van Heyden, Gunther Munz, Lena Schnabel, Ferdinand Schmidt, Svetlana Mintova, Thomas Bein

PII:

S1359-4311(08)00294-9

DOI:

10.1016/j.applthermaleng.2008.07.001

Reference:

ATE 2564

\section{APPLIED}

THERMAL

ENGINEERING

Applied Thermal Engineering

To appear in:

4 December 2007

Received Date:

10 June 2008

Revised Date:

1 July 2008

Accepted Date:

Please cite this article as: H. van Heyden, G. Munz, L. Schnabel, F. Schmidt, S. Mintova, T. Bein, Kinetics of Water Adsorption in Microporous Aluminophosphate Layers for Regenerative Heat Exchangers, Applied Thermal Engineering (2008), doi: 10.1016/j.applthermaleng.2008.07.001

This is a PDF file of an unedited manuscript that has been accepted for publication. As a service to our customers we are providing this early version of the manuscript. The manuscript will undergo copyediting, typesetting, and review of the resulting proof before it is published in its final form. Please note that during the production process errors may be discovered which could affect the content, and all legal disclaimers that apply to the journal pertain. 


\title{
Kinetics of Water Adsorption in Microporous
}

\section{Aluminophosphate Layers for Regenerative Heat}

\section{Exchangers}

Hendrik van Heyden, ${ }^{a}$ Gunther Munz, ${ }^{b}$ Lena Schnabel, ${ }^{b}$ Ferdinand Schmidt, ${ }^{b}$ Svetlana Mintova, ${ }^{*}$ and Thomas Bein $*^{a}$

(a) Department of Chemistry and Biochemistry, University of Munich (LMU), Butenandtstraße 11, 81377 Munich (Germany)

(b) Fraunhofer-Institute for Solar Energy Systems (ISE), Heidenhofstr. 2, 79110 Freiburg (Germany)

(c) Laboratoire de Matériaux à Porosité contrôlée, UMR 7016 CNRS, 3 rue Alfred Werner, 68093 Mulhouse (France), Svetlana.Mintova@ univ-mulhouse.fr, Fax: (+)33 389336885

\begin{abstract}
The performance of thick aluminophosphate molecular sieve layers for heat exchanger applications is evaluated. The aluminophosphate AIPO-18 (AEI structure type code) molecular sieve sorbents is coated on aluminium supports prior the sorption measurements. Two AlPO-18 samples with different morphological appearance, i.e. nano-sized crystals with monomodal size distribution and micron-sized crystals of varying sizes, are used to prepare layers with thickness in the range of $80-750 \mu \mathrm{m}$. As a binder component, polyvinyl alcohol (PVOH) was utilized in order to prepare mechanically stable layers, which are surviving numerous measuring cycles. The sorption measurements are conducted under canonical conditions at $40{ }^{\circ} \mathrm{C}$. The AlPO-18 layers showed decreased mass flows with increasing the thickness. Additionally, the layers comprising nanosized crystals showed higher equilibrium loadings and
\end{abstract}


faster kinetics compared to films based on micron-sized crystals. Following the kinetic studies of pressure, temperature and heat flow, it can be concluded that the heat transport is the rate limiting mechanism for thick aluminophosphate layers. Importantly, the diffusion limitation plays a role only for relatively thin microporous aluminophosphate layers $(<200 \mu \mathrm{m})$. Below this thickness complete heat transfer is achieved within 2 min which allows fast heat exchanger cycles. Thus, the application of microporous aluminophosphate layers for heat transformation and storage applications is considered possible.

\section{Keywords:}

Adsorption, Energy conversion, Kinetics, Thick layers, Aluminophosphate

\section{Introduction}

Adsorption heat pumps utilizing waste heat or solar energy can be based on various solid-vapour working pairs. The three combinations that have received the most attention during the last decade are zeolite/water, activated carbon/ammonia and silica gel/methanol. A comprehensive review of the various concepts for regenerative adsorption systems was given by Lambert et al. [1] Solid/vapour adsorptive systems are very promising for heat transformation applications as they can utilize efficiently solar energy or waste heat as driving force and they can render the burning of fossil fuels for heating much more effective compared to modern condensing boiler heating systems. [2] Therefore, a reasonable amount of the resulted environmental pollution could be avoided. Additionally, non-polluting working media (e.g. water) can be used and the machines are nearly noiseless, as they contain no moving parts. The core of the machine is the adsorber unit, which is composed of the adsorbent and a heat exchanger. To work efficiently, the heat released during adsorption must be quickly transported to the exchanger to ensure minimum cycle times. If the released heat leads to increased temperatures of the adsorbent, its capacity is decreased. [3] Therefore, the design of the adsorber unit is of crucial importance to guarantee fast mass and heat transport. Three different concepts can be distinguished: 1) fine powders distributed in 
exchangers with large metal surface areas, 2) consolidated powders and 3) compact layers prepared on the heat exchanger walls. The first method has a major drawback, as extra material is included in the design and that leads to an extra thermal capacity. Consolidated grains constitute to good vapour transport, but the heat transport is limited due to the point contacts between the individual grains and the heat exchanger wall. The thermal conductivity of the grains themselves can be enhanced by the addition of conductive components. Coating methods improve the heat transfer between the adsorbent and the metal support to a great extent. However, the resistivity within the layer is comparable to consolidated grains and the mass transport is dependent on the structure of the layer. Another problem is the mechanical stability of the coatings and cracking is observed very frequently.

Two concepts used for the preparation of thick layers on metal supports are: (a) the metal support is directly immersed in a synthesis solution therefore leading to direct growth, [4-7] or (b) the material is synthesized in a separate step prior to coating. [8] In the latter case the use of additional compounds, e.g. a binder component is necessary in order to enhance adhesion between the particles and the support. However, coating methods offer advantages over growth methods. The adsorbent can be calcined prior to coating to remove the pore-forming organic template. Calcination of grown layers at temperature around $500-600{ }^{\circ} \mathrm{C}$ can again lead to cracking, as the support and the adsorbent layer generally possess different thermal expansion coefficients. Additionally, grown layers are limited in thickness as the material-specific synthesis solution only contains a limited amount of nutrients. What is more, coating can be easily transferred to larger scale industrial processes, as various methods are known from other surface treatment industries, e.g. spray- or dip-coating.

Various adsorbent materials can be used in heat exchanger applications. Most commonly molecular sieves, in particularly zeolites A (LTA), [4, 6, 7, 9, 10] Y (FAU) [11] or ZSM-5 (MFI) [5] are employed. These materials are commercially available and their sorption characteristic can be tuned by controlling the $\mathrm{Si} / \mathrm{Al}$ - ratio and by post-synthesis ion exchange However, (silico)aluminophosphates, e.g. SAPO-34 or ALPO-18, show superior sorption behaviour, which is depending on their composition and 
morphology. They have improved effective water vapour capacities as the temperature/pressure difference needed for adsorption/desorption is lower. [12-14] Other promising materials include supported salt hydrates [15-20] and metal-organic frameworks. Except of the improved sorption properties, the stability of the used material under process conditions is of importance. We have focused on closed adsorber units working with water as refrigerant. In order to enhance the COP (coefficient of performance) as well as the power density of to-date systems both thermodynamic and kinetic parameters of the materials have been investigated. One of the most promising adsorbent materials in terms of equilibrium data was found to be the microporous aluminophosphate AlPO-18 (AEI structure type code). [14] Under relatively mild conditions, e.g. adsorption at $35{ }^{\circ} \mathrm{C}(1.23 \mathrm{kPa})$ and desorption at $90{ }^{\circ} \mathrm{C}$ (5.67 $\mathrm{kPa})$, it shows useful loadings of up to $28 \mathrm{wt}$. \% depending on the synthesis procedure. [21] Besides equilibrium data kinetics play a crucial role for the overall performance of the adsorber unit. As discussed above, there can be various limiting factors to achievable cycle times. Therefore, we aimed to the preparation of compact layers of various molecular sieves which should reduce limitations due to heat transport to a great extent. Experimental and theoretical investigations concerning kinetics of adsorptive materials for energy applications were carried out among others by Knoche and co-workers. [8] They investigated compact layers of zeolite A and achieved improved mass transfer by addition of melamine as a pore forming agent. Erdem-Senatalar, Tatlier and co-workers developed an improved method for direct synthesis of zeolite A and ZSM-5 on metal surfaces $[4,5,7,22]$ and also investigated the diffusivities of the layers under varying thicknesses. $[6,9,10]$ Aristov and co-workers worked on the kinetics of water adsorption on impregnated silica gel pellets.[15-17, 19, 23] A great work on modelling of various kinetic effects mainly in adsorber beds of palletized zeolites was performed. Among others, the groups of Ruthven, [24-26] Kast [27-30] and Mersmann [31, 32] have simulated the effects of mass and heat resistances as well as non-isothermal adsorption processes. Models for layered geometries were presented by Knoche and co-workers, [8] Tatlier et al.[33] and Dawoud et al. [3, 23]

Kinetic measurements at different adsorptive composite samples at the Fraunhofer Institute for Solar Energy Systems were performed. Composite samples are combinations of adsorbent and metal layer, 
joined together by different technologies. The experimental characterization of composite samples therefore gave information about not only the heat and mass transfer characteristics of the adsorbent layer but also about the heat transfer resistance between adsorbent layer and metal layer. Thus, a realistic evaluation for heat exchanger applications becomes possible. A one-dimensional model has been developed in order to describe properly the evolution of the used experimental setup. [34]

The interest in microporous alumonophosphates is due to the high demand for new highly hydrophilic nanoporous sorbents proper for closed solar cooling system and heat transformation applications. Heat transformation applications based on sorption/desorption of water in nanoporous adsorbents appear to be suitable for many processes where improved thermochemical properties, enhanced hydrothermal and mechanical stabilities are required. For the next generation of chillers and heat pumps, novel adsorbents including nanosized microporous materials (AlPOs, SAPOs, etc.) with properties specifically tailored for these applications will be of great importance.

Here we report on the experimental data concerning sorption kinetics of water vapour in microporous aluminophosphate (AlPO-18) material deposited as thick layers on aluminum support.

\section{Theoretical assumptions}

The overall process of water vapour adsorption in thick layers of microporous adsorbents can be divided in various non-independent processes. For the described applications adsorption is initiated by pressure gradients between a vapour source and a desorbed adsorber unit. The final pressure of the adsorption is defined by the evaporation pressure and the adsorber temperature defining the final loading. The initial loading of the sample at a given temperature defines the initial pressure of the adsorbent layer and in combination with the evaporation pressure the maximal pressure difference. Starting the adsorption by connecting evaporator and adsorber, the vapour instantaneously flows to the layer surface. Then the vapour needs to be transported to the adsorption sites within the microporous crystals. Generally, the composite matrix of microporous crystals, polymeric binder and void volume is considered to represent an idealized macroporous system. This is a critical simplification as the investigated systems are generally 
not ordered. However, it is assumed more or less monomodal distribution of pore diameters with uppermost limits in the range of the crystal dimensions. In this model the walls of this system consist of the microporous AlPO-18 crystals. After vapour transport to the pores, crystals diffusion within the channels of the AlPO-18 takes place. Finally, the adsorption process leads to the release of the corresponding heat of adsorption. In the ideal isothermal case this heat is quickly dissipated to the boundary of the individual crystal, then to the adjacent particle and finally to the heat exchanger wall, i.e. the metal support. For a mathematical description the whole system is normally seen as a network of capacities and resistances. Additionally, one needs to describe the type of diffusion processes at different stages. In this paper we only qualitatively describe the contributing processes.

\section{Macropore diffusion}

The structure of an amorphous network of macropore channels generated during the coating process is difficult to investigate. Sometimes mercury intrusion is used, but standard data interpretation normally assumes bundles of straight capillaries which is a rather strong simplification. Additionally, SEM data can base for a rough estimation of pore diameter and porous structure. Most often the diameter of pores lies in the macroporous range $(>50 \mathrm{~nm})$ and cannot exceed the diameter of the crystals. At 17 mbar the free length of path for water is $7.6 \mu \mathrm{m}$ resulting in a Knudsen number (Eq.1):

$K n=\Lambda / d_{\text {map }} \approx 7.6-76$

for pores with diameters of $0.1-1 \mu \mathrm{m}$. If $\mathrm{Kn}>10$, the determining mechanism of mass transfer is Knudsen diffusion. [35]. Hence, for the investigated samples, free diffusion (described by Fick's law) should only play an inferior role (only for the largest macropores at the highest total pressures). The mass flow is then given by (Eq.2): $[8,35]$ 
$\mathrm{d} m / \mathrm{d} t=-A_{\text {map }} \cdot D_{\mathrm{Kn}} / \mu_{\text {map }} \cdot \mathrm{d} p / \mathrm{d} s$

with Eq. 3+4:

$A_{\text {map }}=A \cdot \Psi_{\text {map }}$

$D_{\mathrm{Kn}}=4 / 3 \cdot d_{\mathrm{map}} \cdot \sqrt{ }\left(M_{\mathrm{g}} / 2 \pi R T\right)$

The mass flow is proportional to the pressure gradient, the cross-sectional area (constant for the investigated samples), the macropore diameter and the structure of the macropore system described by the tortuosity factor $\left(\mu_{\text {map }}\right)$. The pressure gradient generally is a function of position, temperature, loading and absolute pressure, which are dependent on the thermodynamic equilibrium.

\section{Micropore diffusion}

The diffusion coefficient for intra-crystalline diffusion is in the order of $10^{-9}-10^{-8} \mathrm{~m}^{2} \mathrm{~s}^{-1}$, [36] whereas diffusion coefficients for macropore diffusion in pores with diameter of $10^{-7}-10^{-6} \mathrm{~m}$ range between $10^{-}$ ${ }^{4} \mathrm{~m}^{2} \mathrm{~s}^{-1}$ and $10^{-5} \mathrm{~m}^{2} \mathrm{~s}^{-1} \cdot[30]$ However, distances to be covered in micropores are far shorter than those in macropores. Therefore, the micropore diffusion is only the limiting mechanism for thin layers. For instance, macropore diffusion dominates mass transport for grown coatings of zeolite 4A above a thickness of $\sim 100 \mu \mathrm{m}$. [30]

From molecular dynamics simulations it is known that the dependence of loading on the effective diffusion coefficient for small molecules in chabazite related structures is low. [36] Additionally, the effect of absolute pressure on thermodynamics and kinetics of the adsorption process of an individual water molecule is negligible above the saturation limit for AlPO-18. This limit is around $0.1 \mathrm{p} / \mathrm{p}_{0}$ 
$\left(\sim 7.4\right.$ mbar at $\left.40{ }^{\circ} \mathrm{C}\right)$. This can be deduced from measurements on AlPO-18 powders (see Results and Discussion section).

\section{Non-isothermal effects}

If the thermal conductivity between a single microporous crystal and the external heat sink (e.g. the metal support) is poor, non-isothermal effects will be observed, i.e. the crystals heat up during adsorption. [2426] Higher temperatures lead to lower values of equilibrium loading which results in slower overall kinetics. For many detailed investigations this effect plays a dominant role, especially in packed bed geometries and in compact zeolite layers of relatively high masses and at high pressure. However, for thin layers it sometimes is negligible and the layers become exclusively diffusion limited. [9] Generally, the thermal conductivity of a microporous (zeolite) layer decreases with increasing thickness and void volume. Additionally, the contact area between the microporous crystals, which is dependent on size and morphology of the particles and the three-dimensional structure of the whole matrix, affects the conductivity to a great extent. The non-isothermal effect is often underestimated and can have drastic effects, e.g. loading of the layer starting at those regions close to the metal surface as was shown by simulation analysis. [8]

\section{Experimental Section}

Aluminophosphate AlPO-18 synthesis

Nano-sized AlPO-18 crystals were prepared from clear precursor solutions by the use of microwave energy. For the synthesis of micron-sized materials conventional gel syntheses were employed. All powders were calcined in air at $550{ }^{\circ} \mathrm{C}$ for $15 \mathrm{~h}$. The two synthesis procedures are described elsewhere. $[14,37]$

\section{Layer preparation}

The calcined AlPO-18 powders were suspended in double distilled water; polyvinyl alcohol (PVOH, MW $85000-124000$, Aldrich) as binder in form of a $6 \mathrm{wt}$ \% aqueous solution was added to the AlPO-18 
mixture. The final mixtures were stirred overnight to give homogeneous suspensions with a final composition of 16 wt. \% AlPO-18 and 1.6 wt. \% PVOH The 50 x 50 x 0.5 mm aluminium plates (AlMg3 alloy, $\mathrm{Al}>94 \mathrm{wt} . \%$ ) were pre-etched in $2 \mathrm{~N}$ sodium hydroxide solution for $2 \mathrm{~min}$ and rinsed with water. The coating suspensions were deposited manually with a pipette on the aluminium plates. Drying was performed at ambient temperature for $1-5 \mathrm{~h}$.

\section{Characterization}

\section{Aluminophosphates powders and layers}

The aluminophosphate AlPO-18 powders were characterized by means of X-ray diffraction, dynamic light scattering, electron microscopy, thermogravimetric, nitrogen and water physicsorption analyses. All the physicochemical parameters describing the AlPO-18 materials were presented earlier. [14]

The dry layer mass of AlPO-18 layers were determined after heating of the samples to $120^{\circ} \mathrm{C}$ for $1 \mathrm{~h}$. The average thickness of the layers was calculated based on micrometer screw measurements carried out at four different spots. Additionally, the sample surfaces were investigated by scanning electron microscopy using a JEOL JSM-6500F instrument.

\section{Setup for kinetics adsorption measurements}

All AlPO-18 layers were investigated in a standardized procedure in a specially designed measuring setup described below (Figure 1 and Figure 2).

For the kinetic measurements, AlPO-18 layers on aluminium plates $(0.5 \mathrm{~mm})$ are coupled with a special double adhesive tape (3M) to a standardized sample holder, which guarantees a plane surface and a well defined thermal connection to a cold plate (see Figure 1). The thermal connection is ensured with heat conductive paste. Between the sample holder and cold plate a heat flux sensor is situated (not shown). Figure 2 shows the experimental setup used for the kinetic measurements of water. A measuring chamber working at constant temperature contains the AlPO-1 layers and is connected to water vapour reservoir. The latter is fed from the water vapour source that is heated to a defined temperature leading to a defined 
equilibrium pressure. Upon closing this connection (valve 2), the total mass of water vapour in the reservoir is known through by the ideal gas law. Prior to measurements, the measuring cell with the sample is heated to $95{ }^{\circ} \mathrm{C}$ and connected to a vacuum pump for performing the desorption process. When pressure, temperature and heat flux signal are constant the cold plate is cooled to $40{ }^{\circ} \mathrm{C}$. Parallel to the desorption procedure, the water source is kept at 9 or $15^{\circ} \mathrm{C}$ (open valve 2), which is corresponding to a vapour pressure of 11.5 or 17 mbar, respectively. Subsequently two different measuring modes, canonical or isobaric, are performed. For the canonical measurements, valve 2 is closed, thus leading to a constant number of gas molecules in the system. After opening the valve between the measuring chamber and the reservoir (valve 1), the sample instantaneously starts to adsorb, and consequently a decrease in pressure is measured. Since the total volume is known and both vapour pressure and temperature are recorded, the decrease in pressure can be used to calculate the increasing water loading of the adsorber matrix. Besides, the pressure and temperature the heat flux between sample and cold plate is measured and this provides an independent signal to determine the adsorption rate. Data logging runs until the pressure and the heat flux signals become constant. In a subsequent data processing step the amount of water loading is calculated from the measured values of pressures and temperatures and the known volume of the whole device.

\section{Results and Discussion}

\section{Aluminophosphate AlPO-18 powders and layers}

The two types of AlPO-18 powders differ substantially in their morphological features.[14] The nanosized powders posses elongated hexagonal plate-like morphology. The monomodal particle size distribution shows an average particle diameter of $250 \mathrm{~nm}$ corresponding to the long axis of the nonspherical particles. The powders obtained from gel syntheses show undefined morphologies most often of cubic plate-like form. The particle sizes vary from $\sim 0.3 \mu \mathrm{m}$ to $3 \mu \mathrm{m}$. The micron-sized crystals show decreased micropore volumes attributed to a less perfect crystal morphology. 
The layer thicknesses and the corresponding densities of the investigated samples are summarized in Table 1. Layers containing nano-sized crystals ("type N") are denoted as N1 - N4, whereas those containing micron-sized crystals ("type M") are denoted as M1 - M4. Due to the manual coating process the layers show relatively high degrees of surface roughness of up to $10 \%$, however all layers were homogenous over the whole sample area. The two thinnest "type M" layers show increased densities (see Table 1). This is attributed to the mechanism of drying under the applied conditions. The coating suspensions "type M" show decreased stabilities with regard to sedimentation. This leads to an increasing degree of segregation of larger particles from lighter components, i.e. smaller particles and dissolved binder. The effect is more pronounced when longer drying times are used, i.e. in the case of thicker samples. As a homogeneous particle size distribution leads to a more loose packing of crystals, a higher degree of separation is expected to have the same effect.

SEM images of the layer surfaces are shown in Figure 3. Obviously, the inter-particle voids or "macropores" are inhomogeneous in size, shape and structure. This fact is not adequately described in the known mathematical models (see the above section). The macropore diameter estimated from the SEM images is $0.1-1 \mu \mathrm{m}$ for both "type N" and "type M" layers. However, "type N" layers tend to form agglomerates of nano-crystals during the drying process resulting in relatively large voids between them. "Type M" layers do not show agglomeration to the same extent but a rather homogeneous surface. These differences are expected to have an effect on heat and mass transport within the layers.

\section{Kinetic measurements}

All statements in the discussion of the kinetic curves account for the varying total sorbent masses of layers containing nano-/micron-sized AlPO-18 crystals. Layers of comparable total layer masses are plotted in the same style for clarity.

Progression of pressure and mass 
Figure 4 shows the changes of the vapour pressure within the measuring chamber for 17 mbar starting pressure. With increasing sorbent masses, the pressure decrease is generally higher for all samples due to the canonical measuring conditions. The increase of the corresponding mass per surface area of the sample is plotted in Figure 5. As can be seen, "type N" layers of comparable masses (same drawing style in the graphs) show larger pressure decreases at 17 mbar than "type M" layers and therefore higher loadings. This is in a good agreement with the equilibrium sorption data of the corresponding powder samples. [14] In Figure 6 the water loading is normalized to the corresponding layer masses resulting in equilibrium loadings of $275 \mathrm{mg} \mathrm{g}^{-1}$ and $250 \mathrm{mg} \mathrm{g}^{-1}$ for "type N" and "type M" layers, respectively. The water capacities are exceptionally high for microporous molecular sieve materials, thus rendering AlPO18 as a highly interesting compound for heat transformation and storage applications. Additionally, the curves depicted in Figure 6 approach the same equilibrium value for all individual materials showing that the difference in the final pressure is not affecting the reached equilibrium. [38]

To evaluate the differences in kinetics between the individual samples, one has to account for the variety in sorbent mass, as the measurements shown here were conducted under canonical conditions. Based on the achieved pressure at the end of each measurement one can calculate the corresponding points in time during the progression of the measurements, where the pressure was $90 \%$ of the final value. These experimental points in time are summarized in Table 1, and explicitly shown in Figure 7. Based on these (90\% values) one can calculate an average mass and heat flow. The mass and heat flows are plotted against layer mass in Figure 7.

It is found that the water mass flow into the sorbent-binder-matrix decreases with increasing the layer thickness. The "type N" layers show higher mass flows than "type M" with comparable masses. A more detailed analysis of the initial stages of the measurements gives rise to the assumption that different macropore structures are present in the two type layers. The pressure decrease of "type N" layers proceeds along the same mutual decay curve (of exponential type) until a certain degree of saturation is reached. Hence, the limiting mechanism (most probably heat transport) controls the process to the same 
degree at the same time intervals. This is in agreement with the assumption that the microporous crystals are homogeneously distributed along the macropores for the four different layer thicknesses. In contrast, "type M" layers show decreased rates (corresponding to the derivative of pressure, not shown here) with increasing layer masses at same measuring times. As discussed in the introduction section, the heat transport is greatly dependent on the structure of the layers, i.e. the porosity, the total number and area of contacts between the single crystals and the tortuosity of their three dimensional structure. We attribute the differences in the macropore structure of the two type layers to a variation in the structure of the corresponding coating suspensions. It is found that "type M" suspensions show decreased stabilities on the drying time scale (typically $1-4 \mathrm{~h}$ ) compared to "type N" suspensions due to the smaller crystal dimensions. This consecutively leads to an increase in the degree of sedimentation of larger crystals and a separation of lighter components, e.g. polymeric binder and small crystals, to the upper regions of the layer. The described de-mixing effect is more pronounced for higher sorbent masses as the drying time is increased. Therefore thicker layers are more inhomogeneous along the perpendicular axis than the thinner layers. As the "type N" coating suspensions are stable for the time of drying, the resulting layers posses a homogeneous distribution of microporous crystals and macroporous binder matrix. This argumentation can explain the observed differences between layers of variable thickness as well as differences between the two type materials. However, mass transport has to be taken into consideration as a limiting mechanism especially in the case of thin layers.

To examine the nature of the limiting mechanism (either Knudsen diffusion or non-isothermal effects) for the thicker layers we performed measurements on grinded powders obtained by scratching the layers off the aluminium support. It is expected that the Knudsen diffusion should be accelerated and heat transfer retarded in these samples. The results for layer M4 are shown in Figure 8. The powdered sample reaches the $90 \%$ loading level within $18 \mathrm{~min}$ in comparison to $9 \mathrm{~min}$ for the corresponding AlPO-18 layer (sample M4). This indicates that non-isothermal effects play a dominant role for the powdered sample. Based on these data, it cannot be estimated how strong these affect the corresponding compact layer. Therefore both effects have to be taken into consideration. Additionally, the two effects might change 
their significance from the start of adsorption until full saturation is reached, which can be seen from the surface temperature curves. It was demonstrated, that layered systems might not get loaded continuously from the surface to the bottom due to that reason. [8] It is assumed, that after reaching the temperature maximum, the limiting resistance is the heat transport. The material must release heat and further water is adsorbed corresponding to the temperature dependent equilibrium. Further we propose that the samples showing the same heating and cooling behaviour are not controlled by heat transport. This is nearly the case for the thin layers (N1, M1-M2). For all other samples the temperature decay suggests heat transport limitation. As the two effects might change their implication during the whole process, additionally the average mass flow for $20 \%, 50 \%$ and $70 \%$ and $90 \%$ water loading is calculated (Figure 9). The $20 \%$ limit was chosen since the samples approximately reach their heat flux maximum at that time, and the heat transport limitation therefore should be low. With increasing the loading limit, the heat flux limitation increases and the mass flow curves are expected to change their shape. Indeed, the decrease in mass flow is nearly linear with layer mass at the $20 \%$ level due to either mass or heat transport limitation (see below). With increasing the loading, the curves show increasing non-linear behaviour as heavier layers evolve a larger total heat of adsorption, and are therefore more strongly affected by heat limitation.

Comparing the two AlPO-18 crystalline samples, the decrease of mass flow with increasing of layer mass and loading limit is more pronounced for "type M" samples. At the $20 \%$ limit, the relatively thin layers M1 and M2 show a higher average mass flow than the corresponding layer N1. This is in agreement with their higher density (see above) and the higher heat conductivity. It is suggestive that the heat transport is the limiting mechanism even at $20 \%$ loading as a limiting mass transport should be negatively affected by a higher density. The stronger non-linear behaviour of the "type M" layers compared to the "type N" samples at higher loading levels is attributed to the different three-dimensional structures of the adsorbent matrix (see above).

Progression of temperature and heat flux 
Figure 10 shows the temperature development within the measuring chamber in short distance to the sample surface (see Experimental section). The change in the heat flow from the aluminium supports to the constant temperature cold plate is plotted in Figure 11. Additionally, the average heat flow at the $90 \%$ time (integral under the heat flow curve divided by time) is shown in Figure 7. These curves are resulted from the combined effects of mass transport to the microporous crystals, the release of the heat of adsorption and the heat transport to the cold-plate. The different heat transfer resistances during the transport process cannot be separated in the used measuring setup. It can be assumed from the literature data (see Introduction) that the dominant resistance is the transport within the layer rather than intracrystalline- or metal-metal transport. The thermal conductivity of the layer generally decreases with increasing layer thickness and macropore volume as discussed before. The temperature above the sample surface enhances with increasing sorbent mass for both "type N" and "type M" layers. Obviously, none of the layers shows ideal isothermal behaviour. Relatively thin layers (N1, M1, and M2) show fast mass transport. In this case heat transfer, although it is also fast, must be the limiting step for the overall performance. This becomes obvious from the $90 \%$ thresholds for mass and heat transfer dependences shown in Figure 7. For these layers, $90 \%$ heat transfer is reached within 0.5 min after $90 \%$ mass transfer. As complete loading is established quickly, the heat of adsorption is also released after relatively short times (Figure 11) and the temperature goes down to the cold plate level (Figure 10). Especially, layer M2 shows efficient transport properties as the temperature at the surface stays relatively low and the heat signal is large. For thicker layers the time difference between $90 \%$ mass and heat transfer is much shorter probably due to decreased capacitive effects. These effects result from the weight ratio of adsorbing and non-adsorbing material in the investigated samples. In the thinner samples, the contribution of the metal support to the total specific heat capacity of the system is larger rendering the measuring setup more isothermal. Heavier layers show time-dependent temperature plateaus until the mass loading is completed.

\section{Conclusions}


Compact mechanically stable layers of AlPO-18 on aluminium supports were prepared by using polyvinyl alcohol as a binder. The active adsorbent (AlPO-18) was stabilized in an aqueous solution of PVOH to form a homogeneous coating suspension. Two different morphologies, micron-sized crystals from a conventional gel and nano-sized crystals obtained from clear precursor solutions were employed for the preparation of layers.

The mass and heat transfer kinetics of the AlPO-18 layers with different thicknesses were investigated. The results show that the adsorption for layers $<200 \mu \mathrm{m}$ reaches promising values in terms of fast heat and mass transfer characteristics. For layers $>200 \mu \mathrm{m}$ the thermal output and adsorption rate decreased and the overall process proceeded in more than 2 minutes. Additionally, layers comprising nano-sized AlPO-18 crystals show faster kinetics than the corresponding layers containing micron-sized crystals. To account for these differences, most probably non-isothermal effects must be taken into consideration and the degree of limitation also increases with layer thickness. Measurements on AlPO-18 powders of identical chemical compositions showed that this limitation is much stronger in non-layered geometries. Therefore, layered composite concepts are the first choice to establish efficient mass and heat transport in heat exchanger systems. However, diffusion has to be taken into consideration as a limiting mechanism for thin microporous layers.

The AlPO-18 microporous molecular sieves is a promising material for heat exchanger applications as the useful loading under relatively mild conditions exceeds $25 \mathrm{wt} . \%$ and the adsorption kinetics are fast for compact layers up to $\sim 200 \mu \mathrm{m}$ thickness. For thicker layers attempts have to be undertaken to improve both mass and heat transfer in the composites. Promising adsorber geometry for this purpose is the use of relatively thin coatings in the voids of metal foams. [39]

Moreover, the progress in the preparation of composites based on AlPO-18 will enable to develop new products for solar-thermal applications including solar-air-conditioning systems, also will improve conventional heating systems and will subsequently reduce the $\mathrm{CO}_{2}$ emissions. The development of new nanoporous materials for heat pumping and cooling applications has been a research priority for many 
years and by combining the properties of the microporous materials (nanosized AlPO-18) and metal foam matrix will lead to fast adsorption kinetics at controlled adsorbent temperatures.

\section{Acknowledgements}

This work is part of the joint network "New Highly porous materials and systems for energy storage and heat transformation" financed by the German Ministry of Education and Research (BMBF), FKZ01SF0303. Additionally, this work was supported by the Scholarship Programme of the German Federal Environmental Foundation (DBU).

\section{References}

[1] M. A. Lambert, B. J. Jones, Review of regenerative adsorption heat pumps, Journal of Thermophysics and Heat Transfer 19 (4) (2005) 471-485.

[2] S. G. Wang, R. Z. Wang, X. R. Li, -Research and development of consolidated adsorbent for adsorption systems, Renewable Energy 30 (9) (2005) 1425-1441.

[3] B. Dawoud, U. Vedder, E. H. Amer, S. Dunne, Non-isothermal adsorption kinetics of water vapour into a consolidated zeolite layer, International Journal of Heat and Mass Transfer 50 (11-12) (2007) 2190-2199.

[4] A. Erdem-Senatalar, M. Tatlier, M. Urgen, Preparation of zeolite coatings by direct heating of the substrates, Microporous and Mesoporous Materials 32 (3) (1999) 331-343.

[5] M. Tatlier, M. Demir, B. Tokay, A. Erdem-Senatalar, L. Kiwi-Minsker, Substrate heating method for coating metal surfaces with high-silica zeolites: ZSM-5 coatings on stainless steel plates, Microporous and Mesoporous Materials 101 (3) (2007) 374-380. 
[6] M. Tatlier, A. Erdem-Senatalar, Optimization of the thickness of zeolite 4A coatings grown on metal surfaces for heat pump applications, Proceedings of the 12th International Zeolite Conference (1999) 1 583-590.

[7] M. Tatlier, A. Erdem-Senatalar, The stability of zeolite coatings grown on metal supports for heat pump applications, Studies in Surface Science and Catalysis 125 (1999) 101-108.

[8] R. Lang, T. Westerfeld, A. Gerlich, K. F. Knoche, Enhancement of the heat and mass transfer in compact zeolite layers, Adsorption 2 (2) (1996) 121-132.

[9] M. Tatlier, A. Erdem-Senatalar, The effects of thermal and mass diffusivities on the performance of adsorption heat pumps employing zeolite synthesized on metal supports, Microporous and Mesoporous Materials 28 (1) (1999) 195-203.

[10] M. Tatlier, S. B. Tantekin-Ersolmaz, A. Erdem-Senatalar, Diffusivities of zeolite coatings, Studies in Surface Science and Catalysis 135 (2001) 3249-3256.

[11] J. Jaenchen, D. Ackermann, H. Stach, W. Broesicke, Studies of the water adsorption on zeolites and modified mesoporous materials for seasonal storage of solar heat, Solar Energy 76 (1-3) (2004) 339344.

[12] J. Jaenchen, D. Ackermann, E. Weiler, H. Stach, W. Broesicke, Calorimetric investigation on zeolites, $\mathrm{AlPO}_{4}$ 's and $\mathrm{CaCl}_{2}$ impregnated attapulgite for thermochemical storage of heat, Thermochimica Acta 434 (1-2) (2005) 37-41.

[13] H. Kakiuchi, S. Shimooka, M. Iwade, K. Oshima, M. Yamazak, S. Terada, H. Watanabe, T. Takewaki, Water vapour adsorbent FAM-Z02 and its applicability to adsorption heat pump, Kagaku Kogaku Ronbunshu 31 (4) (2005) 273-277.

[14] H. van Heyden, S. Mintova, T. Bein, AlPO-18 nanocrystals synthesized under microwave irradiation, Journal of Materials Chemistry 16 (5) (2006) 514-518.

[15] Y. I. Aristov, I. S. Glaznev, A. Freni, G. Restuccia, Kinetics of water sorption on a $\mathrm{CaCl}_{2}$-in-silicagel-pores sorbent: The effect of the pellet size and temperature, Kinetics and Catalysis 47 (5) (2006) 770-775. 
[16] Y. I. Aristov, I. S. Glaznev, A. Freni, G. Restuccia, Kinetics of water sorption on SWS-1L (calcium chloride confined to mesoporous silica gel): Influence of grain size and temperature, Chemical Engineering Science 61 (5) (2006) 1453-1458.

[17] Y. I. Aristov, I. V. Koptyug, L. G. Gordeeva, L. Y. Il'ina, I. S. Glaznev, Dynamics of water vapor sorption in $\mathrm{CaCl}_{2} /$ silica gel/binder bed: The effect of the bed pore structure, Kinetics and Catalysis 47 (5) (2006) 776-781.

[18] Y. I. Aristov, G. Restuccia, G. Cacciola, V. N. Parmon, A family of new working materials for solid sorption air conditioning systems, Applied Thermal Engineering 22 (2) (2001) 191-204.

[19] Y. I. Aristov, M. M. Tokarev, A. Freni, I. S. Glaznev, G. Restuccia, Kinetics of water adsorption on silica Fuji Davison RD, Microporous and Mesoporous Materials 96 (1-3) (2006) 65-71.

[20] M. A. Stanish, D. D. Perlmutter, Salt hydrates as adsorbents in heat pump cycles, Solar Energy 26 (4) (1981) 333-339.

[21] S. Henninger (ISE Freiburg), unpublished thesis (2007).

[22] M. Tatlier, A. Erdem-Senatalar, Optimization of the cycle durations of adsorption heat pumps employing zeolite coatings synthesized on metal supports, Microporous and Mesoporous Materials 34 (1) (2000) 23-30.

[23] B. Dawoud, Y. Aristov, Experimental study on the kinetics of water vapor sorption on selective water sorbents, silica gel and alumina under typical operation conditions of sorption heat pumps, International Journal of Heat and Mass Transfer 46 (2) (2003) 273-281.

[24] D. M. Ruthven, L.-K. Lee, Kinetics of nonisothermal sorption: systems with bed diffusion control, AIChE Journal 27 (4) (1981) 654-663.

[25] D. M. Ruthven, L.-K. Lee, H. Yucel, Kinetics of non-isothermal sorption in molecular sieve crystals, AIChE Journal 26 (1) (1980) 16-23.

[26] L.-K. Lee, D. M. Ruthven, Analysis of thermal effects in adsorption rate measurements, Journal of the Chemical Society, Faraday Transactions 1: Physical Chemistry in Condensed Phases 75 (11) (1979) 2406-2422. 
[27] W. Kast, Diffusive mass transfer in the transition region between continuum and Knudsen region, Chemie Ingenieur Technik 73 (9) (2001) 1150-1153.

[28] W. Kast, Diffusion of superimposed frictional flow, Waerme- und Stoffuebertragung 29 (7) 447 456.

[29] T. Gutermuth, W. Kast, Kinetics of adsorption and desorption at single particles in relation to overall pressure changes in the surrounding gas phase, Chemie Ingenieur Technik 64 (7) (1992) $650-651$.

[30] W. Kast, Adsorption aus der Gasphase - Ingenieurwissenschaftliche Grundlagen und technische Verfahren, VCH Verlag, Weinheim, 1988.

[31] W. Polte, A. Mersmann, Numerical calculation of the adsorption kinetics of gas mixtures on a $5 \AA$ moelcular sieve, Chemie Ingenieur Technik 58 (7) (1986) 600-601.

[32] W. Polte, S. Scholl, A. Mersmann, Adsorption kinetics of gases on bidispersed adsorbents, Chemie Ingenieur Technik 57 (9) (1985) 789-792.

[33] M. Tatlier, B. Tantekin-Ersolmaz, A. Erdem-Senatalar, A novel approach to enhance heat and mass transfer in adsorption heat pumps using the zeolite water pair, Microporous and Mesoporous Materials 27 (1) (1999) 1-10.

[34] L. Schnabel, H.-M. Henning, Experimental and simulation study on the kinetics of water vapor adsorption on different kinds of adsorptive material metrices, International Sorption Heat Pump Conference 2005 (Broomfield, Colorado).

[35] H.-J. Bart, U. von Gemmingen, Adsorption, in: Ullmann's Encylopedia of Industrial Engineering, 7th Electronic Release ed., Wiley-VCH, Weinheim, 2005.

[36] R. Krishna, J. M. van Baten, Insights into diffusion of gases in zeolites gained from molecular dynamics simulations, Microporous and Mesoporous Materials (2007).

[37] R. Wendelbo, D. Akporiaye, A. Andersen, I. M. Dahl, H. B. Mostad, Synthesis, characterization and catalytic testing of SAPO-18, MgAPO-18. and ZnAPO-18 in the MTO reaction, Applied Catalysis, A: General 142 (2) (1996) L197-L207. 


\section{ACCEPTED MANUSCRIPT}

[38] L. Schnabel, G. Munz, H.-M. Henning, Experimental study on the kinetics of water vapour adsorption, International Conference Solar Air-Conditioning 2005 (Bad Staffelstein, Germany).

[39] L. Bonaccorsi, A. Freni, E. Proverbio, G. Restuccia, F. Russo, Zeolite coated copper foams for heat pumping applications, Microporous and Mesoporous Materials 91 (1-3) (2006) 7-14. 


\section{ACCEPTED MANUSCRIPT}

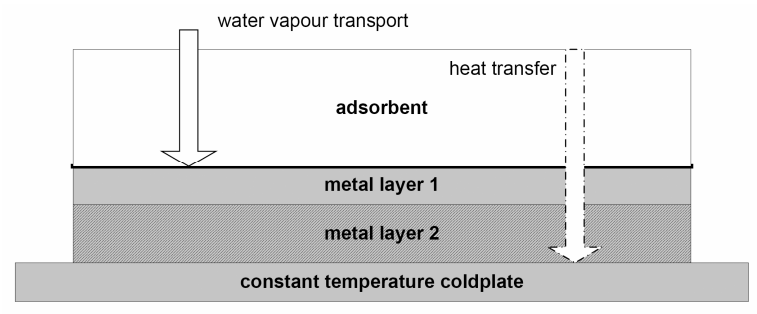

Figure 1. Measuring geometry for the adsorption kinetic measurements on AlPO-18 layers.

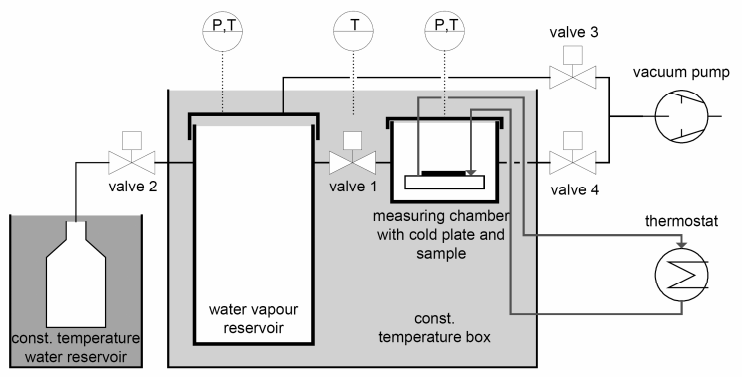

Figure 2. Scheme of the kinetic measurement setup.

a)

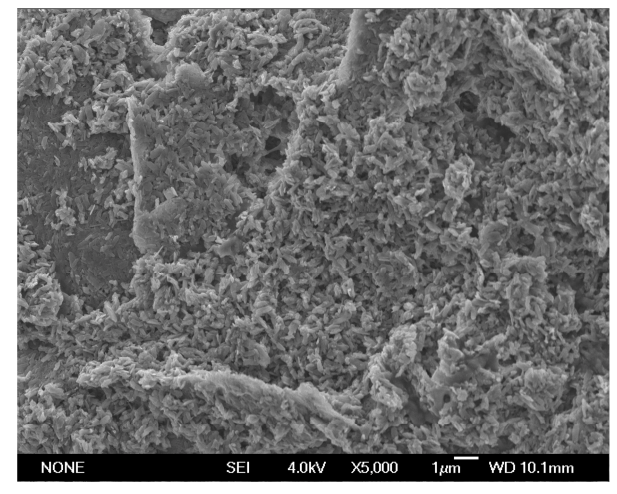

b)

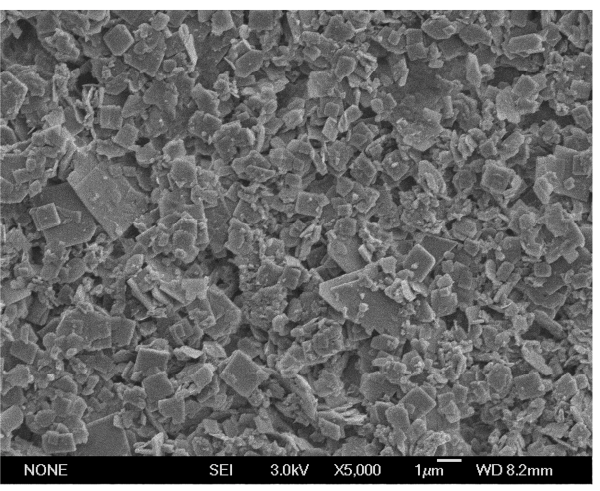

Figure 3. SEM images of a) "type N" and b) "type M" AlPO-18 layers (Scale bar: $1 \mu \mathrm{m}$ ). 
a)

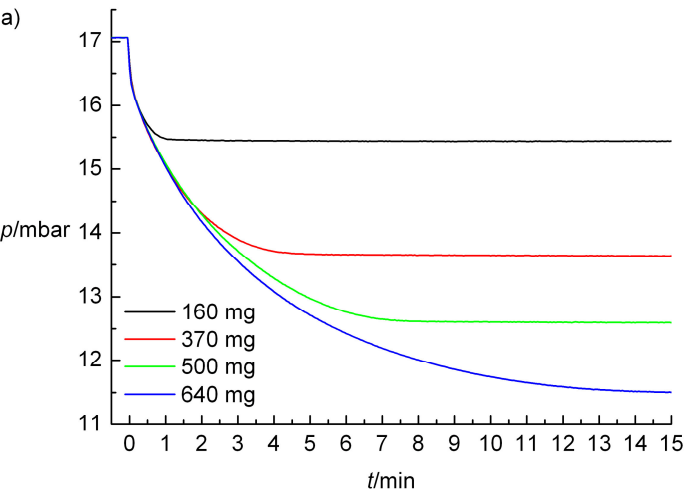

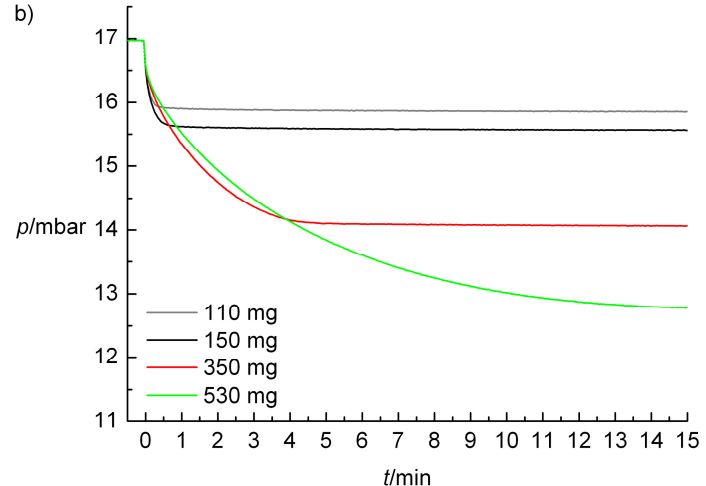

Figure 4. Kinetic curves of the pressure within the measuring chamber at 17 mbar starting pressure of a) “type N" and b) “type M" AlPO-18 layers.
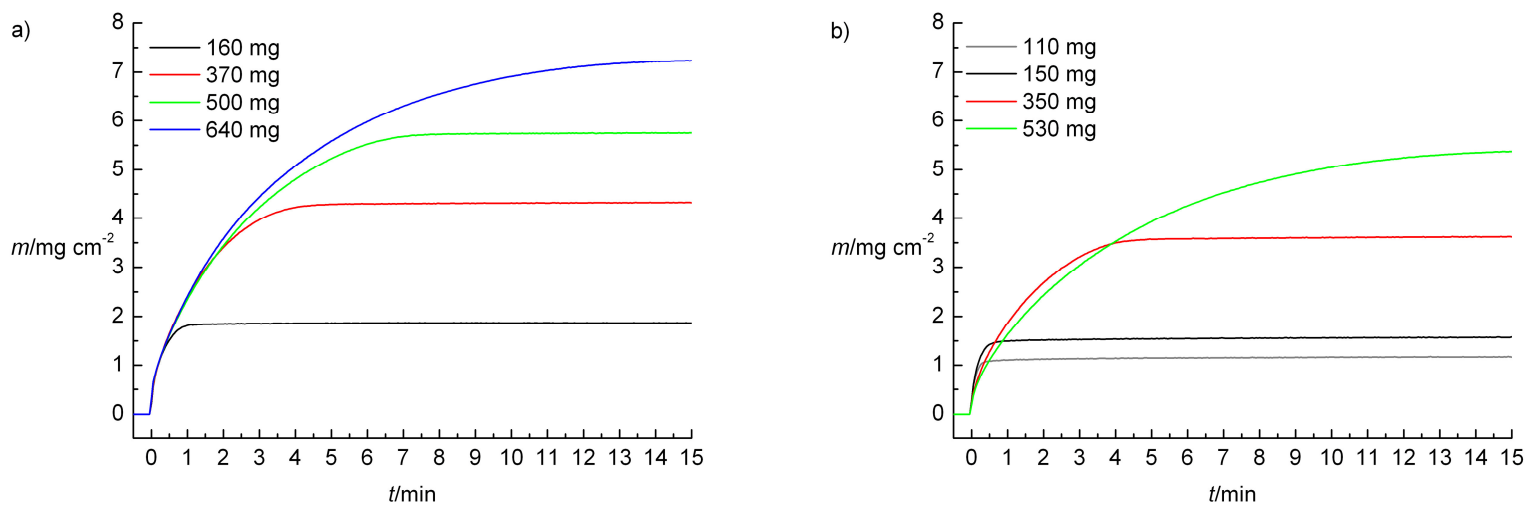

Figure 5. Kinetic curves of $\mathrm{H}_{2} \mathrm{O}$ mass loading per surface area of the aluminophosphate layers. a) "type N", b) “type M". 

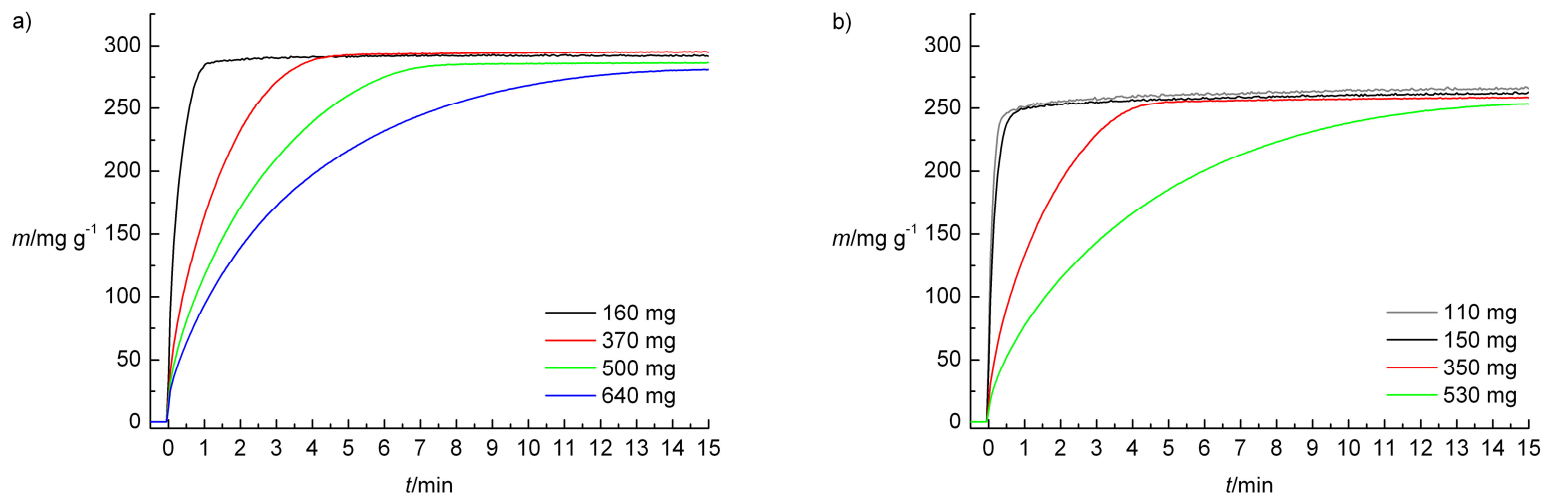

Figure 6. Kinetic curves of $\mathrm{H}_{2} \mathrm{O}$ mass loading per mass of the aluminophosphate layers. a) "type N", b) "type M".
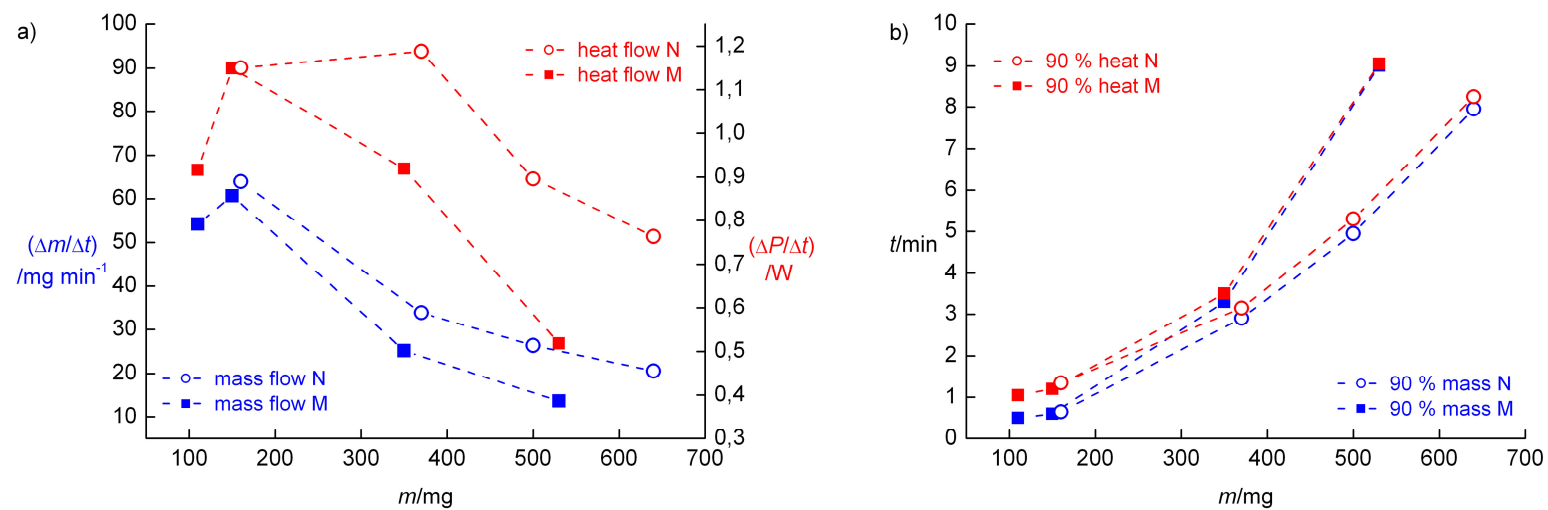

Figure 7. a) Average mass flow (blue) at the point in time where $90 \%$ decrease of the final pressure is reached and the corresponding heat flow (red) b) the same $90 \%$ times versus layer mass. 

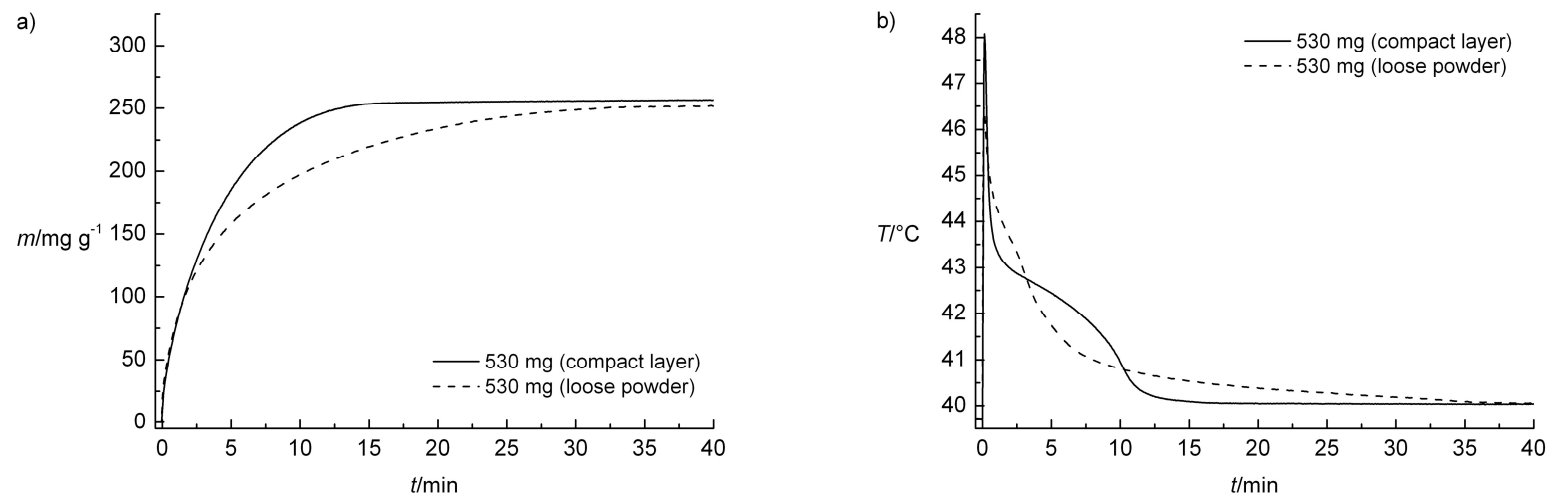

Figure 8. Kinetics of water adsorption on layer M4 compared to a powder AlPO-18 sample:. a) mass weighted loading curve and b) temperature dependent curve.
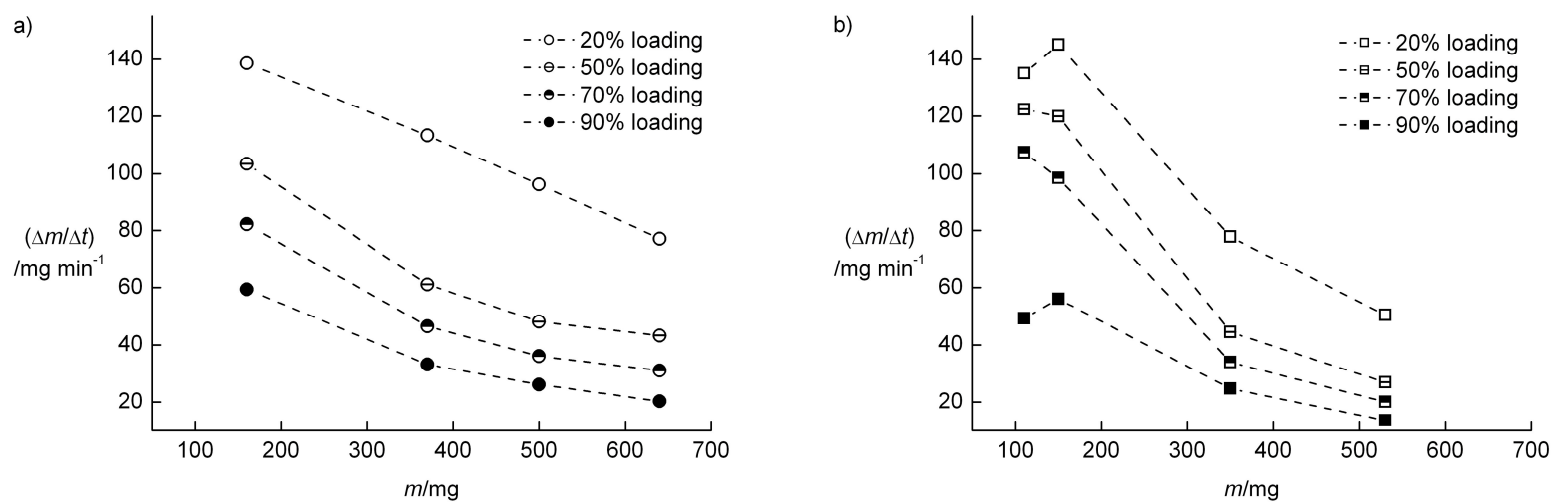

Figure 9. Average mass flows for a) „type N" and b) “type M" layers after 20\%, 50\%, $70 \%$ and $90 \%$ water loading. 

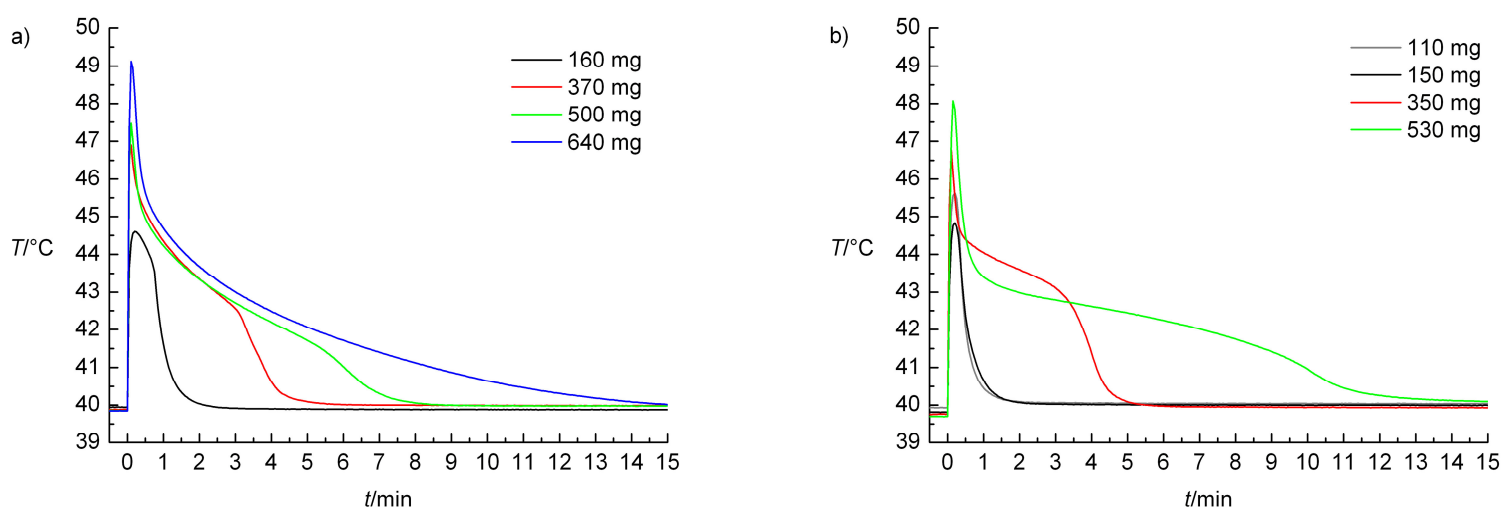

Figure 10. Kinetic curves of the temperature near the surface of the aluminophosphate layers: a) "type N" and b) "type M".
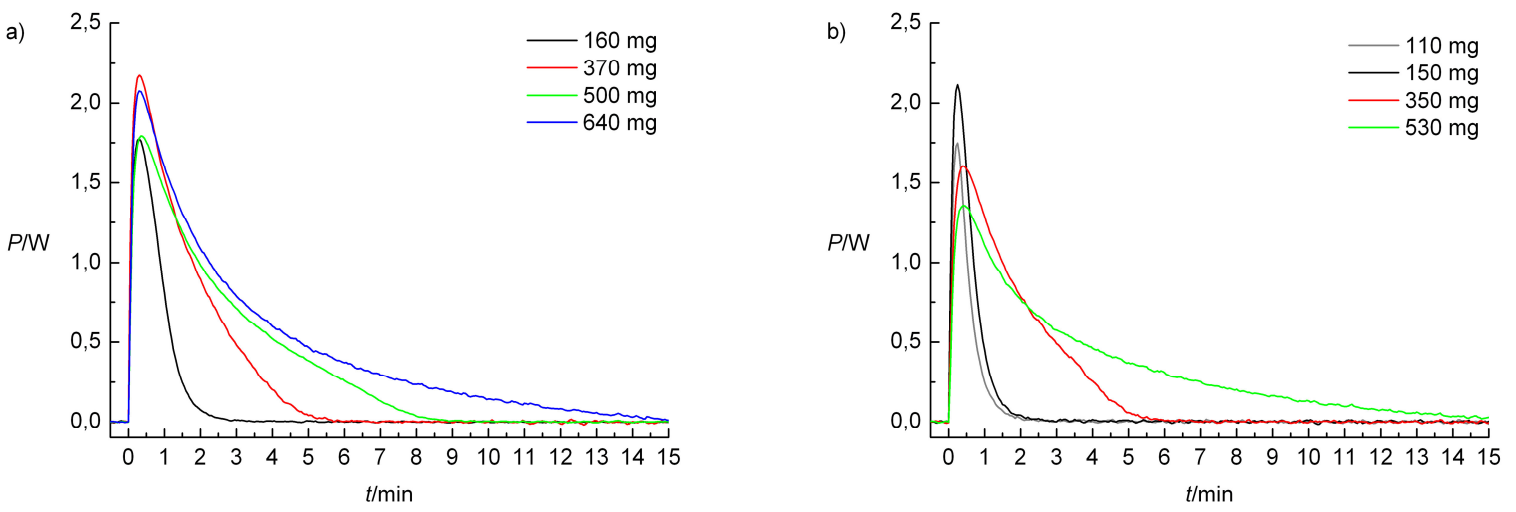

Figure 11. Kinetic curves of the heat dissipation from the aluminophosphate layers: a) "type N" and b) "type M". 
Table 1. Characteristics of microporous AlPO-18 layers.

\begin{tabular}{|c|c|c|c|c|c|c|}
\hline Sample & Dry layer & Effective & Layer & Layer & $90 \%$ & $90 \%$ \\
\hline \multirow[t]{2}{*}{ name } & weight & AlPO-18 & thickness & density & loading & transfer \\
\hline & $(\mathrm{mg})$ & mass (mg) & $(\mathrm{mm})$ & $\left(\mathrm{mg} \mathrm{mm}^{-3}\right)$ & $(\min )$ & (min) \\
\hline M1 & 110 & 99 & 0.08 & 0.55 & 0.45 & 1.05 \\
\hline M2 & 150 & 135 & 0.10 & 0.60 & 0.65 & 1.20 \\
\hline M3 & 350 & 315 & 0.44 & 0.32 & 3.30 & 3.50 \\
\hline M4 & 530 & 477 & 0.62 & 0.34 & 9.00 & 9.05 \\
\hline N1 & 160 & 144 & 0.18 & 0.36 & 0.65 & 1.35 \\
\hline $\mathrm{N} 2$ & 370 & 333 & 0.44 & 0.34 & 2.90 & 3.15 \\
\hline N3 & 500 & 450 & 0.60 & 0.33 & 4.95 & 5.30 \\
\hline N4 & 640 & & 0.76 & 0.34 & 7.95 & 8.25 \\
\hline
\end{tabular}

